Научная статья

УДК 1:001

DOI: 10.18101/1994-0866-2021-4-41-52

\title{
ФИЛОСОФСКИЙ АНАЛИЗ ИННОВАЦИОННОСТИ НАУКИ
}

\section{(c) Павлова Татьяна Петровна}

кандидат философских наук, доцент, Московский авиационный институт

(Национальный исследовательский университет)

Россия, 125993, г. Москва, Волоколамское шоссе, 4

vptp52@mail.ru

Аннотация. Статья посвящена философскому анализу инновационности науки. Актуальность исследуемой проблемы имеет междисциплинарный, синтетический характер. Ее следует рассматривать в контексте развития науки и технологий с акцентом на отраслевые специфики. Технологическая модернизация производства предполагает взаимосвязанные изменения материально-технической базы на основе внедрения инноваций и развития межотраслевых связей.

$\mathrm{XX}$ в. был ознаменован высокой инновационностью в мировой научной деятельности в результате революционных открытий Н. Бора и А. Эйнштейна. Одним из известных ученых, занимающихся философией науки, является Дж. Агасси, который охарактеризовал эти открытия как величайшие, т. к. «до Эйнштейна историки науки не обращали внимания на тот факт, что наука находится в постоянном движении» [1, с. 124]. В конце XX в. в категориальный аппарат философии науки вошло понятие «технонаука». Широкий резонанс получили работы Г. Башляра, Б. Латура, Д. Харви, Ж. Симонда, Д. Харауэй, Е. Мамчур, В. Разина, А. Огурцова, В. Лекторского и других.

Четвертая промышленная революция (Индустрия 4.0) не имеет аналогов в предыдущем опыте человечества. Новые инновации объединяют физические, информационные и биологические миры, способные создать, с одной стороны, огромные возможности, с другой — потенциальную угрозу [17].

Развивающаяся быстрыми темпами в последние годы инновационная деятельность привела к увеличению темпов роста научного знания, что стимулировало развитие наукоемких отраслей промышленности, способствовало экономическому росту и усилению политического влияния стран, занимающих передовые позиции в сфере науки. Наряду с развитием традиционного знания научное творчество порождает новые отрасли прикладной науки: управляемая реакция термоядерного синтеза, клонирование организма животных и человека, создание искусственного интеллекта и т. д. В связи с этим возникает ряд проблем, требующих глубокого анализа с целью определения тенденций инновационной деятельности в современной науке, а именно: определение целей развития науки, взаимоотношение научной инновационности с социумом и природой, определение роли стабильности и революционности в науке, решение проблемы инновационной вседозволенности, нравственное регулирование и контроль инновационных процессов и другие.

Ключевые слова: технонаука, инновационная деятельность, креативность, инновационные технологии, лабораторные исследования, интеллектуализация и рационализация, социальная трансформация, «аксиологическое пространство» науки. 


\section{Для цитирования}

Павлова Т. П. Философский анализ инновационности науки // Вестник Бурятского государственного университета. Философия. 2021. Вып. 4. С. 41-52.

1. Смысл и ценность науки и инновационной деятельности. Научная деятельность неоднородна: существуют разные по своему характеру типы этой деятельности. Фундаментальные науки имеют целью познание объективной реальности такой, какой она есть сама по себе. Результаты прикладных исследований адресованы производителям и заказчикам. Их цель - изменение в нужном для человека направлении природных объектов. Направление науки, связанное со сменой технологических укладов, было разработано выдающимся экономистом И. Шумпетером (1927-), который ввел в научный оборот термин «инновация». Именно смена технологических укладов является движущей силой технологического и социального прогресса, многих кризисов, инноваций, которые переживает современный мир [12].

Большинство современных философов, исследуя науку и инновационную деятельность, отмечают непреходящее значение и важность их устойчивых, нерушимых элементов. В своей работе «Наука в движении», анализируя теорию К. Поппера, Дж. Агасси отмечает, что наука никогда не стоит на месте, что научная деятельность обладает особенностью обновления исследуемых результатов, основным критерием которых является инновационность. Научное познание отличается от познания художественного и философского тем, что научное познание всегда опирается на факты, которые, как правило, дают естественные науки и которые востребованы для практического применения этих инноваций в жизни. «Наука есть постоянная борьба с собой, и она движется вперед благодаря революциям и внутренним конфликтам» [1, с. 121-122].

В статье М. Вебера «Наука как призвание и профессия» подчеркивается отличие научной деятельности от других духовных сфер. Если художественное произведение, которое выражает субъективный взгляд автора на окружающую реальность может быть интерпретирован любым поколением в разное историческое время по-своему и быть актуальным, то научное открытие имеет особенность постоянного наращивания новых знаний, а создание новой техники также постоянно обновляется. Эти изменения зависят не только от естественных условий, но и от развития научно-технического прогресса, организации научных исследований и креативности самих ученых и инженеров.

«Научные работы могут долго сохранять свое значение, оставаясь средством обучения научной работе. Но быть превзойденными в научном отношении - это не только общая судьба всех открытий, но и общая цель. В принципе этот процесс уходит в бесконечность» $[4$, с. 133$]$.

История изобретений и открытий, которая напрямую связана с инженерной деятельностью, в сущности является историей техники как основного компонента общественного производства или истории социально-технического развития человечества. Если рассмотреть последовательность развития представлений о мире с точки зрения технократического подхода, то мы придем к следующей цепочке: первобытная мифология - искусство - философия - естествознание точные науки - техника. Если же представить в качестве основы инновацион- 
ных процессов мыслительную деятельность, связанную с вышеуказанными категориями, то получим цепочку процесса деятельности: мышление в образах вступление в научное мышление - мышление в понятиях — практическое преобразование мира. В то же время любые социальные изменения обусловлены общим типом культуры - «духом эпохи» [2, с. 133].

В социальной философии размывание созерцательной натурфилософской парадигмы происходило в связи с борьбой вокруг вопроса, что положить в основу общественной жизни: «объективные отношения» или «предметную деятельность», давать естественно-историческую или деятельностную трактовку развития. В 70-е годы победила деятельностная точка зрения.

Сейчас предметно-деятельностный подход критикуют за сциентизм, за основание технологической агрессивности. Однако сциентистская компонента в методологии не ослабевает. Предметно-деятельностный подход превращается в мыследеятельность, некую организационно-деятельностную активность-

В 1964 г. Г. П. Щедровицкий выпустил работу «Проблемы методологии системного исследования». В ней он подчеркивал, что инженерная деятельность обладает своей особенностью: «Это очень сложное техническое знание, оно на самом деле намного сложнее, чем научное знание. И работа инженера реально намного сложнее, чем работа ученого» $[11$, с. 12]. Он отмечает в своей работе, что методология организации, руководства и управления инновационными технологиями зависит, с одной стороны, от знания предписаний, с другой стороны, она должна иметь свое особенное, новое представление о создании нового объекта или инновационной технологии.

В различных культурах возникала идея, что люди способны создать подобных им искусственных существ, наделенных собственной волей. Изобретение цифровой вычислительной машины в середине 20-го столетия показало возможности компьютерной техники выполнять вычислительные операции гораздо быстрее, чем это делал человек.

Основоположником кибернетики и искусственного интеллекта считают американского математика Норберта Винера (1894-1964). В своих работах «Кибернетика», «Творец и робот: обсуждение некоторых проблем, в которых кибернетика сталкивается с религией» он впервые рассмотрел проблему соотношения человеческого и машинного мышления. Выступая против машинопоклонников, он разделял функции вычислительной машины и мыслительной деятельности человека [5].

Как отмечает исследователь философии техники Т. Рид, «Винер и первые кибернетики заменили магию наукой, снабдив научной терминологией и респектабельностью идею автономных машин будущего... Эта концепция вдохновила целое поколение инженеров и изобретателей, целью которых стало создать машину по образу человека» [13, с. 498].

В конце XX в. впервые в научный оборот вошло понятие «технонаука». Она выступает как новая реальность научно-технической деятельности, где эффективному использованию потенциала науки способствует не только развитие техники, но и процесс коммерциализации.

Б. Латур (1947-), французский социологи и философ, автор работ «Лабораторная жизнь», «Дайте мне лабораторию, и я переверну весь мир», отмечал, что 
технонаука становится лицом современной науки, а также определяет ее системные изменения. Он впервые поднимает вопросы, которые заставляют по-новому оценить экспериментальную деятельность лаборатории:

- какую роль в получении научного знания играют исследовательские лаборатории,

- до какой степени их выводы влияют на создание новых инновационных технологий,

- несут ли они ответственность за эксперименты над живыми организмами [8].

Постнеклассическая наука отличается своей междисциплинарной направленностью. Технологическая революция в производстве динамических, континуальных, визуальных образов оказала сильное влияние на искусство постмодерна.

Творчество Жана Тенгли, Гюнтера Юккера, Лючио Фонтана, Отто Гине, Хейнца Мака и др. показывает нам, что наш мир синтезирован, а события в нем невероятно и хаотично стандартизованы, но именно в этом мире машин, шума, электроники нам помогут выжить художники, поэты, скульпторы. Так, Ж. Тенгли в 1960 г. в Нью-Йорке строит огромный механический предмет «Слава Нью-Йорку», который создается только на один вечер. Удивительно, как удалось художнику показать нам на «языке машин» всю трагедию этого города, когда конструкция, представлявшая собой кучу железного лома, над которой возвышались сломанные колеса, сорванные со всех видов транспорта, тросы, целая масса других предметов, медленно двигалась, скрипела, вступая в непосредственный контакт со зрителями, и медленно-медленно разрушалась. Несмотря на все смешные, агрессивные или гротескные элементы, это строение с самого начала вызывало атмосферу размышления, потому что во всех действиях этого непонятного механизма прослеживалась тема недолговечности, недостаточности и безумия. Ж. Тенгли писал: «Я замечаю, что со временем мои машины все дальше отходят от потешного характера, который был им долго свойственным... Они постепенно переходят в область трагического. Нам так трудно жить в этой неразберихе, которую мы сами себе создали, в том техническом винегрете, которым мы нафаршировали себе голову» [15, с. 27-28].

Обобщая эти тенденции, можно утверждать, что научно-техническая инновационная деятельность занимает преобладающее место в современной истории человечества. Исследуя природу креативности инженерной деятельности, многие исследователи подчеркивают, что творчество человека зависит от его интеллектуального развития, от личностных качеств, таких как самодостаточность, стремление к самореализации, от умения мыслить и принимать нестандартные решения. Креативность и интеллект не зависимы друг от друга, хотя и находятся в тесной взаимосвязи. Здесь хочется вспомнить Иммануила Канта, который в своей работе «Критика способности суждения» описал различия между гением и талантом.

Концепция устойчивого развития направлена на реализацию способностей научной и инженерной деятельности для блага человека, прогнозируя основные направления науки и техники в будущем. Она выражает тенденцию к укрупнению и усложнению инженерно-конструкторской деятельности, а также пониманию невозможности добиться решения инновационных задач без умения управлять коллективами и творческими личностями. Инженерная деятельность 
направлена на принятие решений, способствующих устойчивому развитию системы «природа - общество - человек». Ведущим компонентом этой системы является человек, осуществляющий целесообразную деятельность в соответствии с собственными потребностями. Однако инновационные новшества имеют амбивалентный характер. С одной стороны, они позволяют человеку решить множество проблем, возникающих в техносфере и социуме. С другой стороны, технический прогресс приводит к росту непредвиденных негативных последствий, которые невозможно ни прогнозировать, ни контролировать. Таким образом, невозможно представить инновационные процессы без всемерного расширения рамок их восприятия в жизнедеятельности общества, увеличения числа участников, непосредственно занятых в реализации этих процессов, а также расширения доступа к их результатам в обществе.

2. Свобода инновационности науки. Актуальность проблемы обострена вследствие кардинально меняющихся за последние десятилетия представлений. М. Хайдеггер в своей работе «Отрешенность» отмечает: «Мир теперь представляется объектом, открытым для атак вычисляющей мысли, атак, перед которыми уже ничто не сможет устоять... Страшно на самом деле не то, что мир становится полностью технизированным. Гораздо более жутким является то, что человек не подготовлен к этому изменению мира» [16, с. 107-108]. Все существование человека в ноосфере пронизано воздействием научно-технических новаций, начиная с бытовых изобретений и заканчивая глобальными проектами изменения окружающего мира.

Каково возможное разрешение сложившейся ситуации? Ведь условием творчества, его продуктивности является свобода, а свобода инновационности в науке становится все более непредсказуемой. В конце XX в. в научном сообществе развернулась дискуссия по поводу свободы научных изысканий и их ограничения правительственным регулированием. Эта дискуссия до сих пор находит сторонников, которые утверждают, что научные исследования не должны подчиняться директивам, которые властные структуры создают для контроля за научным сообществом. По их мнению, это вмешательство угрожает научной свободе и тормозит инновационные процессы.

С другой стороны, многие ученые признают правильность определенного регулирования государственными структурами особенно тех инноваций, которые касаются исследований, связанных с ДНК, клонированием человека и других.

Донна Харауэй (1944-), американский философ и историк сознания, предлагала проект новой идентичности личности в современной эпохе в работах «Манифест киборгов», «Оставаться с проблемой». Основное направление ее исследований - создать новую идентичную личность в современную эпоху. По ее мнению, сегодня гендерное, расовое и классовое сознание перестали обеспечивать веру в цельную человеческую личность. Она призывает с помощью гендерной инженерии создать альтернативу «естественной идентификации» - постгендерный мир гибридных организмов (киборгов) [18].

Много вопросов в отношении свободы личности и новых информационных технологий поднимают в связи с появлением в научном исследовании такого понятия, как «киберпространство». Можно ли считать свободой интеллекта новое 
субъективное видение и поведение личности под воздействием созданного симулякра этим киберпространством?

Делая добровольный выбор вхождения в виртуальное пространство, человек начинает его воспринимать как настоящую реальность. Примером может быть виртуальный город Хэбитэт, созданный в Японии (Кодзуми, 1995). Каждый, кто имеет доступ в интернет, может стать жителем этого города - «аватаром». При оформлении гражданства «человеку предлагается выбрать себе внешний вид, подобрать одежду. Город Хэбитэт существует уже четыре года, и его численность достигает 10 тыс. человек. В этом городе жители живут «полноценной» личной и общественной жизнью: работают, общаются, делают открытия, выбирают правительство и т. д.» [14, с. 211-212].

Проблема будущего развития общества и человека, как мы видим сегодня, неразрывно связана с новыми соотношениями между деятельностью человека и интеллектуальными инновационными технологиями. Несмотря на то, что научное познание заинтересовано в поиске истины, в ведении диалога, общении между членами научного сообщества, правомерно признать и то, что гражданское общество также имеет право спросить, какой результат будет в будущем от научных исследований ученых и инженеров.

На наш взгляд, процесс творчества ограничен тем, что сегодня коммерциализация стимулирует развитие прикладных дисциплин, нежели фундаментальных наук. Кроме того, этот процесс влияет на ценностную ориентацию ученых. Работая на определенные заказы от разных государственных и частных структур, у ученых появляются личные интересы в карьерном росте, получении дополнительного финансирования и т. д.

Развитие информационных технологий, создание искусственного интеллекта помогают качественно изменить общество, но они могут нести и угрозу этому обществу. В концепции устойчивого развития общества, на которую ориентируется все мировое сообщество, оговариваются вопросы ответственности, этического поведения, мер безопасности при разработке этих инновационных проектов и проведении оценки их возможных последствий. Это осуществляется через создание различных кодексов деятельности как ученых, так и инженеров.

Концепция коэволюции, предложенная Н. Н. Моисеевым (1917-2000), предполагала согласованное эволюционное взаимодействие, гармоничное сосуществование природы и человека, конвергенцию всех типов материальных систем, которые были направлены на отрицание деструкций и негативных последствий человеческой деятельности. Размышляя над новыми инновациями, он писал: «Я бесконечно боюсь революций - ни одна из них не приводила к целям, которые они декларировали... действовать следует очень осмотрительно, но думать надо революционно» $[9$, с. 16].

Исследуя процессы инновационности, В. А. Кутырев отмечает: «Надо всячески поощрять тенденцию к науке без воплощения инновационности, т. е. без обязательного материального результата. Математики выводят уравнения, не заботясь об их применении, физики-теоретики так увлекаются абстрактными моделями мира, что перестают интересоваться их экспериментальной проверкой. Это позволяет сгладить противоречия между свободой творчества и задачами сохра- 
нения природы, исторической памяти, другими потребностями человечества» [7, c. 77].

3. Интеллектуализация и рационализация НТП. Анализируя взаимоотношение человека и окружающего мира, современные философы отмечают усиление в нем влияния субъективного инновационного вектора и наряду с этим парадоксальную тенденцию к потере творчества.

Как управлять инновациями? Как их стимулировать? В мире науки известны лаборатории Белла (Bell Laboratories), где выдающиеся ученые совершают научные открытия также эффективно, как и прибыльные ноу-хау. Речь идет о входящих в состав американской телекоммуникационной компании Lucent Technologies так называемых Bell Labs, сотрудники которых неоднократно получали высшую награду научного сообщества. В лаборатории Белла сделали свои открытия более десяти нобелевских лауреатов, именно там изобрели транзистор и создали лазер (по сути, одновременно с российскими физиками). Вицепрезидент Bell Labs Роберт Мартин на вопрос о главной идее, которая стимулирует инновации, отвечал так: «Есть два основополагающих принципа жизни нашей организации. Первый - это непрерывные инновации, а второй - неизменное стремление к техническому совершенству. В каком-то смысле это технократическая идеология... У нас работают представители самых разных национальностей и культур» [10].

Философский анализ эволюции социальных систем позволяет сделать вывод об огромной роли высоких темпов информатизации для их жизнеспособности и функциональности. Президент Всемирного экономического форума в Давосе Клаус Щваб, говоря о востребованности степени креативности работников, подчеркивал значимость их интеллектуальных способностей для работодателя при устройстве на работу. Это требование характеризуется новым понятием «контекстуальный интеллект». Определение контекста содержит в себе умение работника предвидеть зарождающиеся инновации, умение определить их риски, потребные затраты на их осуществление, а также знания, необходимые для их осуществления [17, с. 173-175].

Таким образом, возрастающие темпы интеллектуализации и рационализации не обязательно приводят к росту ценностных знаний человечества, а лишь обеспечивают обществу уверенность в том, что с помощью технических средств и расчета можно решить все.

Постклассическая наука получила свое развитие в связи с переходом к изучению сложных иерархически развивающихся систем и использованием новых методов исследования. Возникает вопрос, каким образом относиться к инновационности науки и дальнейшей интеллектуализации общества в условиях сложившегося представления о них. Решению этой проблемы посвящен доклад М. Вебера «Наука как призвание и профессия», где он определил главное отличие тех, кто занимается наукой, от тех, кто преподает эту науку в учебных заведениях. «Путь дальнейшей интеллектуализации человечества заключается не в безудержном пропагандировании научно-технических инноваций, а гармоничном слиянии бытия, науки и среды обитания, когда нужно обратиться к своей работе и соответствовать «требованию дня» - как человечески, так и профессионально» $[4$, с. 149$]$. 
Как отмечает Г. Бехманн в работе «Современное общество: общество риска, информационное общество, общество знаний», информационное общество направлено на производство знаний, что приводит к увеличению доли умственного труда в системе разделения труда. Эти изменения требовали новых структурных преобразований образовательной среды, которые должны были трансформировать ее в открытую систему. «Спрос на научное знание увеличивается, но требуются новые методы размышления о будущем, коммуникации с будущим. В результате возникают новые интерфейсы между различными дисциплинами, в том числе социально-гуманитарными...» [3, с. 71].

Традиционные требования к квалифицированному труду были основаны на наличии образования с набором определенных знаний. Компаративистское исследование этой проблемы подтверждает, что модернизация университетского образования наиболее удачно начала осуществляться в Англии и Германии в период Нового времени. Содержание двух концепций образования Дж. Ньюмена и В. Гумбольдта заложили основы образовательной деятельности во многих странах мира. Различие этих образовательных концепций заключалось в том, что в Англии закладывались программа и идеи интеллектуального образования, а в Германии акцент был сделан на исследовательскую деятельность и значимость ее практического применения. Сегодня чаще всего эти две концепции диалектически взаимосвязаны. Проблемы современного образования обусловлены требованием внедрения в образовательную среду новых инноваций в рамках цифровой промышленной революции.

Фактически происходит изменение образовательной среды обучения, где центральное место принадлежит не столько преподавателю как носителю информации, сколько «визуальному образу», который основан на экраннокомпьютерном потоке изображений, вкладывающих в себя самую разнообразную информацию - текстовую, графическую. Данный вид обучения построен на новом способе коммуникации между преподавателем и обучающимися. Используя различные источники получения знаний, обучающийся применяет различные приемы их поиска, оценку разных интерпретаций, что требует глубокого погружения в их контекст. Именно такая мыслительная работа является обязательным условием понимания научного исследования. В виртуальном пространстве вполне реальна опасность поверхностного, недостаточного в смысловом отношении описания фактов, различных точек зрения на политику, нравственные ситуации. Эта работа требует хороших знаний и навыков методологии научного исследования, которая стоит как основная задача перед образовательными учреждениями.

4. Определенность «аксиологического пространства» - база для развития науки. Процесс привнесения чуждых научных традиций в определенное «аксиологическое пространство» (конкретную национальную почву) возможен, причем он всегда связан с созданием новационного научного сообщества и укоренением научных знаний на новой почве. Это можно рассмотреть на примере России XVII-XVIII вв. Оценивая этот сложный период становления науки, В. О. Ключевский писал: «Что же так осложнило русскую жизнь этого века? Реформы, начатые предшественниками Петра и им продолженные. Эти реформы были предприняты частью под влиянием Западной 
Европы. До той поры русское общество жило влияниями туземного происхождения, условиями собственной жизни и указаниями природы своей страны. C XVII в. на это общество начала действовать иноземная культура, богатая опытом и знаниями. Это пришлое влияние встретилось с доморощенными порядками и вступило с ними в борьбу, волнуя русских людей, путая их понятия и привычки, осложняя их жизнь, сообщая ей усиленное и неровное движение» [6, с. 13].

Сегодня проблема укоренения деятельности науки и искусства в «аксиологическом пространстве» стоит очень остро. Потеря своих культурных корней вызвана не только обстоятельствами и судьбой. Утрата укорененности исходит из самого духа техногенной цивилизации. «Мы задумаемся еще и спросим: если это так, смогут ли еще и впредь человек и его творения корениться в плодородной почве его родины и тянуться к эфиру, на простор небес и духа? Или же все попадет в тиски планирования и калькуляций, организации и автоматизации» [16, с. 106]. Осмысляя сказанное М. Хайдеггером, мы видим, что процессы миграции усиливаются и веку планетарной техники грозит полная утрата корней. Мартин Хайдеггер считал, что наука и техника это не просто человеческое дело, это дарованная человеку способность с их помощью раскрыть глубинные свойства Бытия. Сутью этого способа познания является «поставление истины». Поэтому технику он называет «постав» (нем. hestell - постов, станина). Это позволяет человеку говорить с Бытием, слышать его, представляет Бытие в подлинном, неискаженном виде.

Затормозить исторический ход научно-технической инновационности или подчинить себе этот процесс общество не способно, поэтому возникает проблема: насколько успешно человечество сможет обрести новую почву для развития и новое «аксиологическое пространство» для выяснения собственной сущности. Социум зависит от технических приспособлений и постепенно оказывается крепко связанным техническими новациями, но социум одновременно способен сказать «нет», когда затрагивается человеческая сущность. М. Хайдеггер назвал это отношение одновременно «да» и «нет» миру техники старым словом - «отрешенность от вещей». Человек везде видит возможность приложения своих деятельно-познавательных способностей. Хайдеггер считал, что техника - важнейший способ обнаружения глубинных свойств Бытия, с помощью которой можно проникнуть в его тайны. Отказаться от применения техники в научном исследовании сегодня невозможно, но когда человек ради коммерческих планов покушается на свою сущность, он забывает, что он - часть живой природы. Хайдеггера так же, как и других исследователей, интересовал ответ на вопрос: «В чем смысл техники?»

Этот скрытый смысл повсюду затрагивает человека в мире техники и, обращаясь к смыслу, личность оказывается внутри области, называемой тайной мира техники. М. Хайдеггер называет поведение, благодаря которому человечество открывается для смысла, потаенного в мире техники, «открытостью для тайны». Деятельность человека оказывает влияние на характеристику положительного или отрицательного смысла технического преобразования Бытия. 
Таким образом «отрешенность вещей» и «открытость тайне» дадут человечеству возможность обрести новое «аксиологическое пространство», где будет дана возможность творить новое и вести диалог культур «всех народов мира». Инновации науки в широком смысле создают особую деятельность, в рамках которой не только создаются технические новшества, но и осуществляется трансформация духовных сфер социума.

\section{Литература}

1. Агасси Дж. Наука в движении // Структура и развитие науки (из Бостонских исследований по философии науки). Москва: Наука, 1978. 423 с. Текст: непосредственный.

2. Бахтин М. М. Эстетика словесного творчества. Москва: Искусство, 1979. 445 с. Текст: непосредственный.

3. Бехманн Готхарт Современное общество: общество риска, информационное общество, общество знаний. 2 изд. Москва: Логос, 2011. 248 с. Текст: непосредственный.

4. Вебер Макс Наука как призвание и профессия // Самосознание европейской культуры XX века: мыслители и писатели Запада о месте культуры в современном обществе. Москва: Политиздат 1991. 368 с. Текст: непосредственный.

5. Винер Н. Творец и робот: обсуждение некоторых проблем, в которых кибернетика сталкивается с религией. Москва: Прогресс, 1966. 104 с. Текст: непосредственный.

6. Ключевский В. О. Неопубликованные произведения. Москва: Наука, 1983. 415 с. Текст: непосредственный.

7. Кутырев В. А. Осторожно, творчество // Вопросы философии. 1994. № 7-8. С. 88-104. Текст: непосредственный.

8. Латур Б. Дайте мне лабораторию, и я переверну весь мир / перевод с английского П. Куслий. 2002. № 5-6(35). C. 211-242. URL: http://www.ruthenia.ru /logos/number/35/10.pdf (дата обращения: 30.09.2021). Текст: электронный.

9. Моисеев Н. Н. Судьба цивилизации. Путь разума. Москва: Языки русской культуры. 2000. 224 с. Текст: непосредственный.

10.Нобелевский инкубатор: интервью Дана Медовникова и Елены Рыцаревой // Проектирование будущего. Роль нанотехнологий в новой реальности. Эксперт. 2000. № 40. URL: https://www.nanonewsnet.ru/articles/2009/proektirovanie-budushchego-rol-nanotekhnolo gii -v-novoi-realnosti (дата обращения: 30.09.2021). Текст: электронный.

11.Путеводитель по методологии организации, руководства и управления: хрестоматия по работам Г. П. Щедровицкого. Москва: Дело, 2003. 160 с. Текст: непосредственный.

12.Малинецкий Г. Г. Проектирование будущего. Роль нанотехнологий в новой реальности. URL: https://www.nanonewsnet.ru/articles/2009/proektirovanie-budushchego-rolnanotekhnologii-v-novoi-realnosti (дата обращения: 30.09.2021). Текст: электронный.

13.Рид Т. Рождение машин: неизвестная история кибернетики. Москва: Эксмо, 2019. 544 с. Текст: непосредственный.

14.Севальников А. Ю. Онтологические аспекты виртуальной реальности // Виртуалистика: экзистенциальные и эпистемологические аспекты. Москва: Прогресс-Традиция, 2004. 383 с. Текст: непосредственный.

15.Тэнгли Ж. Каталог по случаю выставки работ Жана Тэнгли в Москве в марте 1990 г. Цюрих, 1990. 151 с. Текст: непосредственный.

16. Хайдеггер М. Разговор на проселочной дороге. Москва: Высшая школа, 1991. 192 с. Текст: непосредственный.

17.Шваб К. Четвертая промышленная революция. Москва: Эксмо, 2019. 288 с. Текст: непосредственный. 
18.Donna Haraway. A Cyborg Manifesto: Science, Technology, and Socialist Feminism in the Late Twentieth Century // Simians, Cyborgs and Women: The Reinvention of Nature. New York: Routledge, 1991. P. 149-181.

Статья поступила в редакиию 28.09.2021; одобрена после рецензирования 05.10.2021; принята к публикациии 15.11.2021.

\section{PHILOSOPHICAL ANALYSIS OF THE INNOVATIVENESS OF SCIENCE}

\section{Tatyana P. Pavlova}

Cand. Sci. (Philos.), A/Prof.,

Moscow Aviation Institute

(National Research University),

4 Volokolamskoe Highway, Moscow 125993, Russia

vptp52@mail.ru

Abstract. The article presents the philosophical analysis of the innovativeness of science. The problem under study has an interdisciplinary, synthetic nature, and should be considered from the perspective of the development of science and technology with an emphasis on industry specificities. Technological modernization of production involves interrelated changes in facilities and resources based on the introduction of innovations and development of inter-industry relations.

$20^{\text {th }}$ century was marked by high innovation in the world scientific activity as a result of the revolutionary discoveries of N. Bohr and A. Einstein. One of the famous scientists involved in the philosophy of science is J. Agassi, who characterized these discoveries as the greatest, because "before Einstein, historians of science did not pay attention to the fact that science is in constant motion" [1, p. 124]. At the end of the $20^{\text {th }}$ century the concept of "technoscience" entered the categorical apparatus of the philosophy of science. The works of G. Bachelard, B. Latour, D. Harvey, J. Simond, D. Haraway, E. Mamchur, V. Razin, A. Ogurtsov, V. Lektorsky and others received a wide response. The fourth industrial revolution (Industry 4.0) has no analogues in the previous experience of mankind. New innovations combine physical, informational and biological worlds that can create, on the one hand, huge opportunities, and, on the other, a potential threat [17].

The rapidly developing innovation activity in recent years has led to an increase in the growth rate of scientific knowledge, which stimulated the development of knowledgeintensive industries, contributed to economic growth and increased political influence of countries that occupy leading positions in the field of science. Along with the development of traditional knowledge, scientific creativity gives rise to new branches of applied science: controlled thermonuclear reaction, cloning of animal and human organisms, creation of artificial intelligence, etc.

In this regard, a number of problems arise that require deep analysis in order to determine the trends of innovative activity in modern science, namely, defining the goals of science development, relationship of scientific innovation with society and nature, determining the role of stability and revolutionism in science, dealing with the problem of innovative permissiveness, moral regulation and control of innovation processes and others.

Keywords: technoscience, innovation activity, creativity, innovative technology, laboratory research, intellectualization and rationalization, social transformation, "axiological space" of science. 
For citation

Pavlova T. P. Philosophical Analysis of the Innovativeness of Science. Bulletin of Buryat State University. Philosophy. 2021; 4: 41-52.

The article was submitted 28.09.2021; approved after reviewing 05.10.2021; accepted for publication 15.11.2021. 